\title{
Clinical and Laboratory Characteristics of Patients with Infective Endocarditis: A Single-Center Experience
}

\author{
Enfektif Endokardit Hastalarının Klinik ve Laboratuvar Özellikleri: \\ Tek Merkez Deneyimi \\ Sümeyye Kazancıoğlu' ${ }^{1}$, Esragül Akıncı ${ }^{2}$, Burcu Özdemir ${ }^{1}$, Aliye Baştuğ $\breve{g}^{2}$, \\ Adalet Aypak ${ }^{1}$, Hürrem Bodur ${ }^{2}$ \\ ${ }^{1}$ Ankara City Hospital, Department of Infectious Diseases and Clinical Microbiology, Ankara, Turkey
}

${ }^{2}$ Health Science University Turkey, Ankara City Hospital, Department of Infectious Diseases and Clinical Microbiology, Ankara, Turkey

Yazışa Adresi / Correspondence:
Sümeyye Kazancioğlu
Ankara City Hospital, Department of Infectious Diseases and Clinical Microbiology Üniversiteler Mahallesi 1604. Cadde No: 9 Çankaya/ ANKARA
T: +90505375 $0336 \quad$ E-mail : sumeyye_yildiz@hotmail.com

Geliş Tarihi / Received : 12.02.2021 Kabul Tarihi / Accepted: 05.07.2021

Orcid :

Sümeyye Kazancioğlu https://orcid.org/0000-0003-3869-6130

Esragül Akıncı https://orcid.org/0000-0003-3412-8929

Burcu Özdemir: https://orcid.org/0000-0002-1851-3539

Aliye Baștuğ: https://orcid.org/0000-0002-8831-4877

Adalet Aypak: https://orcid.org/0000-0001-8850-2475

Hürrem Bodur: https://orcid.org/0000-0001-7455-1049

(Sakarya Tip Dergisi / Sakarya Med J 2021, 11(3):561-570 ) DOI: 10.31832/smj.874951

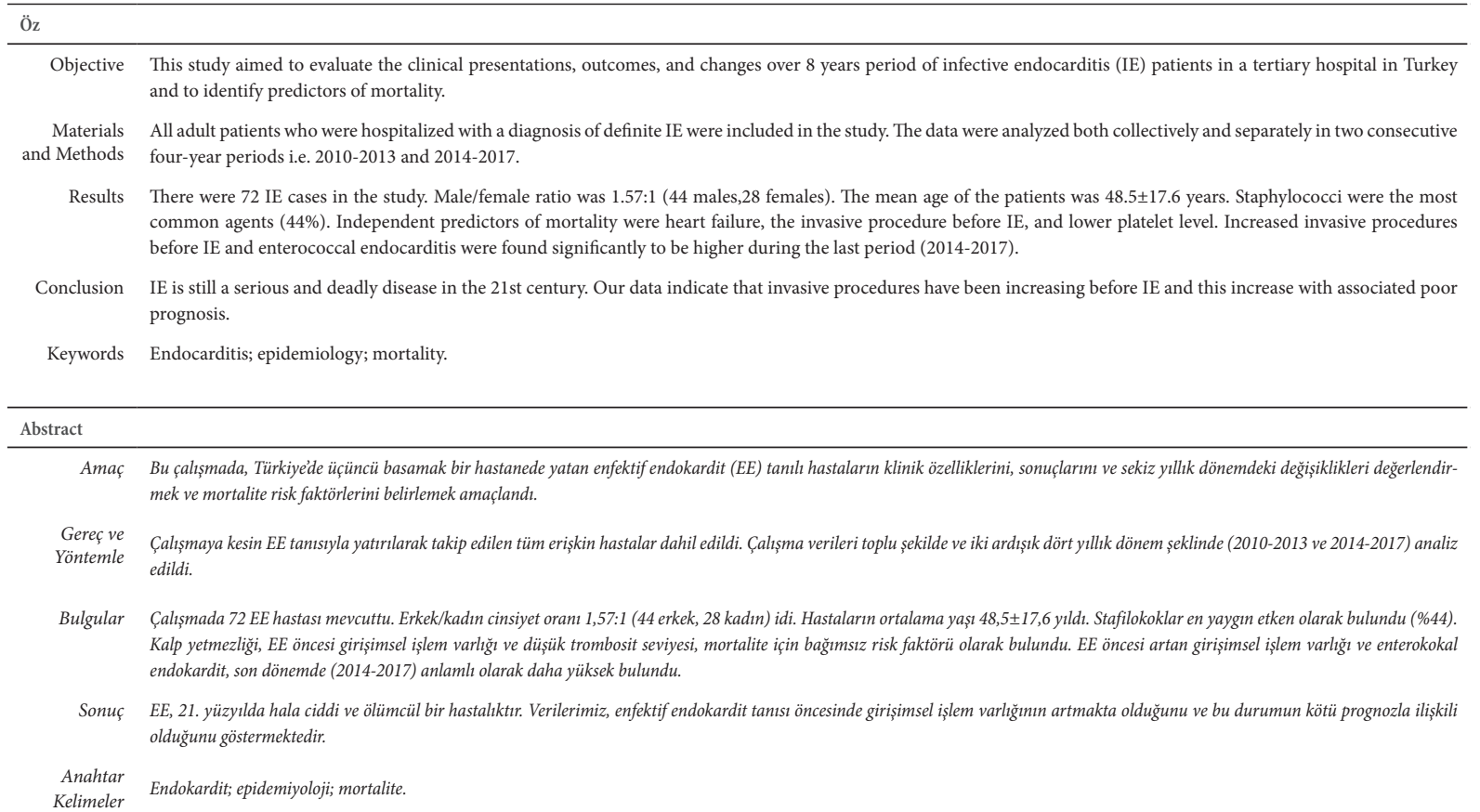




\section{INTRODUCTION}

Infective endocarditis (IE) is a rare but severe infectious disease with increased incidence in recent years. ${ }^{1,2} \mathrm{IE}$ is related to high costs because of prolonged hospitalization and can require surgical improvement. Risk factors for IE clinical spectrum have changed in the last decades with increased health care procedures; including intracardiac devices, central venous catheterization, hemodialysis. ${ }^{3-5}$ Several studies have noted an increase in the proportion of IE caused by staphylococcal species. ${ }^{4,6}$

Although blood culture is a major criterion for diagnosis for IE, culture-negative endocarditis remains an important clinical situation. ${ }^{2,7}$ The current in-hospital mortality rate for IE is $15-30 \%$, with one-year mortality approaching $40 \%{ }^{1,2,8-11}$ Despite advances in diagnosis (including imaging techniques such as cardiac CT, F-FDG PET/CT, or leucocytes labeled SPECT/CT and treatment, mortality and several complications rates are still high. ${ }^{2}$

This study aimed to evaluate the clinical presentations, etiology, echocardiographic findings, outcomes, and changes in characteristics of IE patients in a tertiary hospital in Turkey over 8 years and to identify predictors of mortality.

\section{MATERIALS and METHODS}

The ethics committee of the Ankara Numune Training and Research Hospital approved this study design (confirmation date and number: 29.03.2017, 1320/2017). This study was conducted by the principles of the Declaration of Helsinki.

\section{Study design}

This study is a retrospective observational cohort study. All adult patients (age $\geq 18$ years) who were hospitalized in a tertiary hospital in Turkey with a diagnosis of IE between 2010 and 2017 were included in the study.

IE was identified by searching in the main discharge diagnoses of hospitalizations for the ICD-10-CM (Internation- al Classification of Diseases) codes I33.0(acute and subacute endocarditis), I38 (endocarditis, valve unspecified), and I33.9(acute endocarditis, unspecified) in the hospital information management system.

Patients' dead or alive information was obtained from the national death notification system data. Information on 12-month-mortality after the time of admission was obtained using each patient's civil registration number. Centralized registration of death based on the individual civil registration number is unique for Turkey and guarantees a $100 \%$ follow-up.

The search identified 94 patients with a diagnosis of IE. All of these patients' clinical records were reviewed. Patients with definite IE according to the modified Duke criteria were included in the study. Twenty-two patients who did not meet the inclusion criteria and/or whose all of the data were not available were excluded. Eventually, 72 patients were included in the study.

\section{Data extraction}

Each IE patient extracted data into a data collection form. The following variables were recorded for each patient: age, sex, duration of illness before hospital admission ( $>1$ month), previous antibiotic use (within three months before admission), history of recent medical procedures ( including dental, gastrointestinal, genitourinary and central venous catheterization, within six months before admission), underlying cardiac predisposition (congenital heart disease (CHD), chronic rheumatic heart disease (CRHD), or degenerative heart diseases), comorbid conditions before IE (diabetes mellitus, chronic renal failure, coronary artery disease, hypertension, chronic obstructive pulmonary disease (COPD), being on chronic haemodialysis, malignancy and/or immunosuppression, intravenous drug use (IVDU), admission complaints, physical investigation findings, laboratory values (blood urea nitrogen, serum creatinine, C-reactive protein (CRP), alanine aminotransferase (ALT), aspartate aminotransferase (AST), total bil- 
irubin, rheumatoid factor, haemoglobin level, platelet and white blood cell (WBC) counts, erythrocyte sedimentation rate (ESR), urinalysis test (hematuria and proteinuria) at the time of diagnosis), blood culture results, echocardiography findings, antimicrobial treatments, surgical interventions, cardiac and extracardiac complications (neurological events, embolism, congestive heart failure, renal failure) and mortality. Mortality was defined as death occurring within 12 months after diagnosis. These data were primarily analyzed in general. Secondarily, all data were evaluated in two periods of 4-year intervals (2010-2013, 2014-2017).

\section{Statistical analyses}

Statistical analyses were done using SPSS for Windows version 17.0 (IBM Corporation, Armonk, NY, USA). Variables were found to be significant $(\mathrm{p}<0.05)$. The distribution of continuous variables was investigated with the Kolmogorov-Smirnov test. The significance of the difference between the mean values of the groups was assessed by Student's t-test, variables with a non-normal distribution were compared using the Mann-Whitney U test. The ChiSquare and Fisher's tests were used to compare categorical variables. Factors that might be the most determinative factors of mortality were investigated by multivariate stepwise logistic regression analysis. As a result of univariate analysis, all variables identified as $\mathrm{p}<0.25$ were taken by a multivariable logistic regression model as candidate risk factors. Also, odds ratios, 95\% confidence interval, and wald statistics for each variable were calculated.

\section{RESULTS}

During this 8-year study period, a total of 72 IE cases (44 males, 28 females) were identified in the study. The mean age of the patients was $48.5 \pm 17.6$ years. 47 patients (65\%) had one or more comorbidities. The most common underlying condition was hypertension (33.3\%). Two patients were intravenous drug users. There was no HIV-positive patient in this cohort. Presence of an invasive procedure within six months before the diagnosis of IE was found in 27 patients (37\%). Of all cases, 43 (59.7\%) had received a previous course of antibiotic therapy. Forty patients (55.6\%) were admitted after one month of the initial signs of illness. Among 72 endocarditis episodes, 25\% involved prosthetic valves $(n=18)$ and $8.3 \%(n=6)$ were device-related. The most predisposing cardiac risk factors were CRHD $(n=27,37.5 \%)$ (Table 1). Seven patients had degenerative and five patients had congenital heart disease. The most frequent symptoms were fever $(88.2 \%)$, myalgia $(79.2 \%)$, dyspnea (62.5\%) and clinical signs were fever (\%90.3), heart murmur (75), and splenomegaly (34.7). The other symptoms and findings of the patients are presented in Table 2.

\section{Echocardiographic features}

All patients underwent transthoracic echocardiography (TTE) and half of the patients' transesophageal echocardiography (TOE). Eight patients' TTE's were negative for IE. Seven of these patients had positive TOE. In one patient there was a contraindication therefore TOE couldn't be performed. Valvular involvement was present in 62 patients (86\%). Native valve endocarditis was present in 48 patients $(67 \%)$. Prosthetic valve and pacemaker/ICD endocarditis were seen in 18 patients (25\%) and 6 patients (8\%), respectively. Mitral (44\%) and aortic valves (32\%) were infected most commonly. The vegetation was $10 \mathrm{~mm}$ more in size in $45(62.5 \%)$ patients and mobile vegetation was observed in $44(61.1 \%)$ patients. Paravalvular complications occurred in $25(34.7 \%)$ patients. Half of the fatal cases had these complications.

\section{Microbiological data and antimicrobial susceptibility}

The causative microorganism was identified in 48 patients (66.67\%) by positive blood culture. Staphylococci (S. aureus $n=14$, coagulase-negative staphylococci (CoNS) $n=7$ ) were the most isolated microorganisms $(n=21,44 \%)$, followed by streptococci $(n=12,25 \%)$ and enterococci $(n=8$, $17.0 \%)$. Other microorganisms were identified as two Candida spp., two Brucella spp., and three gram-negative rods (two Pseudomonas spp. and one E.coli). The rate 
Sakarya Med J 2021;11(3):561-570

KAZANCIOĞLU et al., Evaluation of Patients with Infective Endocarditis

Table 1. Demographic characteristics and predisposing conditions of patients with infective endocarditis.

\begin{tabular}{|l|c|c|c|c|}
\hline & $\begin{array}{c}\text { Patients who survived } \\
(\mathrm{n}=46)\end{array}$ & $\begin{array}{c}\text { Patients } \\
\text { who died }(\mathrm{n}=26)\end{array}$ & Total patients $(\mathrm{n}=72)$ & $\mathrm{p}$-Value \\
\hline Age, years & $45.1 \pm 16.2$ & $54.7 \pm 18.7$ & $48.5 \pm 17.6$ & $\mathbf{0 . 0 2 5} \dagger$ \\
\hline Male gender & $27(58.7 \%)$ & $17(65.4 \%)$ & $44(61.1 \%)$ & $0.758 \ddagger$ \\
\hline Total length of hospital stay, days & $30(2-59)$ & $13(2-78)$ & $25(2-78)$ & $\mathbf{0 . 0 2 7}$ \\
\hline First sign to admission $>1$ month & $25(54.3 \%)$ & $15(57.7 \%)$ & $40(55.6 \%)$ & $0.978 \ddagger$
\end{tabular}

Cardiac risk factors

\begin{tabular}{|l|c|c|c|c|}
\hline Chronic rheumatic heart disease & $20(43.5 \%)$ & $7(26.9 \%)$ & $27(37.5 \%)$ & $0.254 \ddagger$ \\
\hline
\end{tabular}

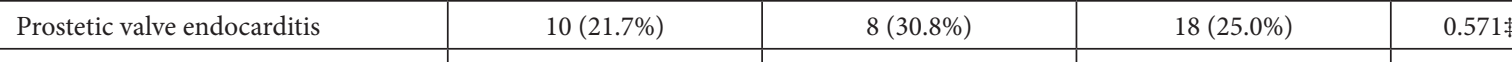

\begin{tabular}{|l|c|c|c|c|}
\hline Pacemaker/ICD & $6(13.0 \%)$ & $0(0.0 \%)$ & $6(8.3 \%)$ & $0.081 \$$ \\
\hline Comorbidities & $24(52.2 \%)$ & $21(80.8 \%)$ & $45(62.5 \%)$ & $\mathbf{0 . 0 3 1}$ \\
\hline
\end{tabular}

Coronary heart diseases

Diabetes mellitus

Hypertension

Chronic renal failure

Chronic haemodialysis

$5(10.9 \%)$

$12(26.1 \%)$

$4(15.4 \%)$

$9(12.5 \%)$

$0.714 \$$

Malignency and/or immunosupp-ression

Chronic obstructive lung diseases

Previous antibiotic use within 90 days

Invasive procedure within 6-month

Central venous catheterization

\begin{tabular}{|c|c}
\hline $12(26.1 \%)$ & $12(46.2 \%)$ \\
\hline $6(13.0 \%)$ & $7(26.9 \%)$ \\
\hline $4(8.7 \%)$ & $5(19.2 \%)$ \\
\hline $5(10.9 \%)$ & $4(15.4 \%)$ \\
\hline $3(6.5 \%)$ & $1(3.8 \%)$ \\
\hline $26(56.5 \%)$ & $17(65.4 \%)$ \\
\hline $13(28.3 \%)$ & $14(53.8 \%)$ \\
\hline $7(15.2 \%)$ & $8(30.8 \%)$ \\
\hline
\end{tabular}

\begin{tabular}{|c|c|}
\hline $17(23.6 \%)$ & $0.712 \ddagger$ \\
\hline $24(33.3 \%)$ & $0.140 \ddagger$ \\
\hline $13(18.1 \%)$ & $0.202 \$$ \\
\hline $9(12.5 \%)$ & $0.269 \$$ \\
\hline $9(12.5 \%)$ & $0.714 \$$ \\
\hline $4(5.6 \%)$ & $>0.999 \$$ \\
\hline $43(59.7 \%)$ & $0.627 \ddagger$ \\
\hline $27(37.5 \%)$ & $0.057 \ddagger$ \\
\hline $15(20.8 \%)$ & $0.208 \ddagger$ \\
\hline
\end{tabular}

$\dagger$ Student's t-test, Data is median \pm SD. $\ddagger$ Chi-Square test, Data are $\mathrm{n}(\%)$. Mann Whitney U test, Data are median (min-max). \$ Fisher's test, Data are n (\%).

\begin{tabular}{|l|c|c|c|}
\hline Table 2. Presenting symptoms and clinical findings of patients with infective endocarditis. & Findings & Number (\%) \\
\hline Symptoms & Number (\%) & Fever & $52(86.1)$ \\
\hline Fever & $65(90.3)$ & Heart murmur & $13(18)$ \\
\hline Myalgia & $57(79.2)$ & Petechiae & $25(34.7)$ \\
\hline Artralgia & $20(27.8)$ & Splenomegaly & $4(5.5)$ \\
\hline Lack of appetite & $30(41.7)$ & Janeway lesion & $10(13.8)$ \\
\hline Cough & $27(37.5)$ & Osler nodes & $7(9.7)$ \\
\hline Dispne & $46(62.5)$ & Roth spot & $39 / 57(54.1)$ \\
\hline Weight loss & $10(13.9)$ & Hematuria & $67(93)$ \\
\hline Headache & $10(13.9)$ & Elevated C-reactive protein & $60(83.3)$ \\
\hline & & Elevated sedimentation rate & $10 / 18(13.9)$ \\
\hline
\end{tabular}


of methicillin resistance was $28.6 \%(4 / 14)$ for S. aureus strains and $57.1 \%(4 / 7)$ for CoNS strains. Viridians group streptococci were identified in 8 patients, four streptococcus species couldn't be identified. Three streptococcus strains were resistant to penicillin. Among the enterococci, seven species were identified as Enterococcus faecalis. One strain identified as Enterococcus faecium was resistant to ampicillin and vancomycin.

\section{Treatment}

The median length of antibiotic treatment was 23.5 (2-45) days. The most commonly used antibiotic was $\beta$-lactams \pm aminoglycosides $(n=34,47.2 \%)$. Then respectively, daptomycin \pm aminoglycosides $(n=22,30.6 \%)$, vancomycin \pm aminoglycosides \pm rifampicin $(n=11,15.3 \%)$, antifungal agents $(n=2)$, rifampicin \pm doxycycline \pm ceftriaxone $(n=2)$ and meropenem $(n=1)$ were used.

Although the surgical intervention was decided for 42 patients(58\%), only 15 (20.8\%) patients underwent surgery due to contraindication or patient rejection.

\section{Outcome}

The median length of hospital stay was 25 days (min-max, 2-78). The hospital stay was significantly longer in the non-fatal group $(\mathrm{p}=0.027)$. Clinical complications during hospital stay included: embolic events in 35 (48.6\% of patients), congestive heart failure in 22 (30.6\% of patients), and renal failure in $22(30.6 \%)$ patients.

Overall, 22 patients (30.6\%) were discharged with full recovery. A follow-up of 12 patients (16.7\%) continued at the outpatient parenteral antibiotic treatment (OPAT) unit. All of these patients were recovered at the end of treatment. Ten of the patients (13.9\%) were referred to another hospital because of surgical intervention. The overall hospital mortality rate was $26.4 \%$ (19/72), the 12 -month mortality rate was $36.1 \%(26 / 72)$. In the univariate analysis, the parameters that increased mortality were older age, presence of the comorbid condition, left-sided endocardi- tis, renal and heart failure, embolic event, central nervous system (CNS) emboli and/or infarct, lower thrombocyte count, higher urea, creatinine, and bilirubin levels (Table 1,3 and 4).

As a result of univariate analyses, all variables identified as $\mathrm{p}<0.25$ were taken by a multivariable logistic regression model as candidate risk factors for mortality. The following parameters were included in logistic regression analysis as age, hypertension, chronic renal failure, the invasive procedure before IE, central venous catheterization, WBC, neutrophils, platelets, hemoglobin, CRP, creatinine, AST, total bilirubin, aortic involvement, paravalvular abscess, perforation, rupture of the leaflet, heart failure, renal failure, cranial emboli and/or infarct, lung embolism. Three factors were independently associated with mortality: Heart failure OR: 29.3 (95\% CI: 5.9-145.2, p<0.001), invasive procedure before IE OR: 6.8 (95\% CI: 1.5-31.3, $\mathrm{p}=0.013$ ), lower platelet level OR: 1.1 (95\% CI: 1.03- 1.20, $\mathrm{p}=0.003$ ) (Table 5).

\section{Changes in patients characteristics of IE}

Patients characteristics were evaluated in two periods; 2010-2013 ( $\mathrm{n}=28)$ and 2014-2017 $(\mathrm{n}=44)$. Invasive procedure before IE (21.4\% vs $47.7 \%)$ and enterococcal endocarditis $(0.0 \%$ vs $48.2 \%)$ were significantly more prevalent in patients during 2014-2017 period ( $\mathrm{p}=0.046, \mathrm{p}=0.019$, respectively). All pacemaker lead infections $(n=6)$ occurred during the last period. The first sign to admission after a month rate was higher in the 2014-2017 period (45.5\%, 71.4\% respectively). But these conditions were not statistically significant $(\mathrm{p}=0.075$ and $\mathrm{p}=0.055$, respectively). Patients' laboratory, echocardiographic findings, and mortality rates were similar between the two periods. Mortality rates were $39.3 \%$ and $34.1 \%$ respectively.

\section{DISCUSSION}


Sakarya Med J 2021;11(3):561-570

KAZANCIOĞLU et al., Evaluation of Patients with Infective Endocarditis

Table 3. Laboratory findings of patients with infective endocarditis.

\begin{tabular}{|c|c|c|c|}
\hline & Patients who survived $(\mathrm{n}=46)$ & Patients who died $(n=26)$ & Total patients $(n=72)$ \\
\hline $\mathrm{WBC}, / \mu \mathrm{L}$ & $10000(3100-22600)$ & $12700(2600-49000)$ & $11300(2600-49000)$ \\
\hline Neutrophils, $/ \mu \mathrm{L}$ & $7750(600-213300)$ & $10900(100-112000)$ & $8150(100-213300)$ \\
\hline Thrombocycte count, $/ \mu \mathrm{L}$ & $240782.6 \pm 80161.8$ & $162038.5 \pm 122101.7$ & $212347.2 \pm 103793.3$ \\
\hline Hemoglobin, g/dL & $11.2 \pm 2.1$ & $10.4 \pm 2.6$ & $10.9 \pm 2.3$ \\
\hline Hematocrit, \% & $34.0 \pm 6.0$ & $32.1 \pm 7.7$ & $33.28 \pm 6.68$ \\
\hline Urea, mg/dL & $30.5(11-232)$ & $80.5(19-203)$ & $43.5(11-232)$ \\
\hline Creatinine, $\mathrm{mg} / \mathrm{dL}$ & $0.9(0.3-9.4)$ & $1.9(0.4-9.0)$ & $1.0(0.3-9.4)$ \\
\hline ALT, U/L & $17.5(3-182)$ & $20.5(2-267)$ & $19.5(2-267)$ \\
\hline AST, U/L & $22(9-107)$ & $24(13-169)$ & $22.5(9-169)$ \\
\hline Total bilirubin, $\mathrm{mg} / \mathrm{dL}$ & $0.7(0.3-2.5)$ & $1.1(0.3-10.1)$ & $0.7(0.3-10.1)$ \\
\hline $\mathrm{CRP}, \mathrm{mg} / \mathrm{L}$ & $62(2-361)$ & $101(6-343)$ & $73(2-361)$ \\
\hline Sedimentation, $\mathrm{mm} / \mathrm{h}$ & $48.2 \pm 24.8$ & $42.8 \pm 35.3$ & $46.5 \pm 28.29$ \\
\hline
\end{tabular}

Table 4. Echocardiographic features, microbiologic etiology, and outcome of patients with infective endocarditis

\begin{tabular}{|c|c|c|c|c|}
\hline & Patients who survived $(\mathrm{n}=46)$ & Patients who died $(n=26)$ & Total patients $(\mathrm{n}=72)$ & $\mathrm{p}$-Value \\
\hline Left-sided IE & $33(71.7 \%)$ & $25(96.2 \%)$ & $58(80.6 \%)$ & $0.028 \dagger$ \\
\hline \multicolumn{5}{|l|}{ Valvular involvement } \\
\hline Aortic & $11(23.9 \%)$ & $12(46.2 \%)$ & $23(31.9 \%)$ & $0.093 \dagger$ \\
\hline Mitral & $21(45.7 \%)$ & $11(42.3 \%)$ & $32(44.4 \%)$ & $0.978 \dagger$ \\
\hline Tricuspid & $4(8.7 \%)$ & $1(3.8 \%)$ & $5(6.9 \%)$ & $0.647 \ddagger$ \\
\hline Two valves & $1(2.2 \%)$ & $2(7.7 \%)$ & $3(4.2 \%)$ & $0.294 \ddagger$ \\
\hline Vegetation size of $\geq 10 \mathrm{~mm}$ & $31(67.4 \%)$ & $14(53.8 \%)$ & $45(62.5 \%)$ & $0.375 \dagger$ \\
\hline Mobile vegetation & $29(63.0 \%)$ & $15(57.7 \%)$ & $44(61.1 \%)$ & $0.845 \dagger$ \\
\hline Perivalvuler complications & $12(26.1 \%)$ & $13(50.0 \%)$ & $25(34.7 \%)$ & $0.074 \dagger$ \\
\hline Paravalvuler abscess & $3(6.5 \%)$ & $5(19.2 \%)$ & $8(11.1 \%)$ & $0.128 \neq$ \\
\hline Perforation & $1(2.2 \%)$ & $4(15.4 \%)$ & $5(6.9 \%)$ & $0.054 \ddagger$ \\
\hline Rupture of the leaflet & $5(10.9 \%)$ & $7(26.9 \%)$ & $12(16.7 \%)$ & $0.104 \ddagger$ \\
\hline Complications & $21(45.7 \%)$ & $23(88.5 \%)$ & $44(61.1 \%)$ & $<0.001 \dagger$ \\
\hline Heart failure & $5(10.9 \%)$ & $17(65.4 \%)$ & $22(30.6 \%)$ & $<0.001 \dagger$ \\
\hline Renal failure & $6(13.0 \%)$ & $12(46.2 \%)$ & $18(25.0 \%)$ & $0.005 \dagger$ \\
\hline Embolic events & $17(37.0 \%)$ & $18(69.2 \%)$ & $35(48.6 \%)$ & $0.017 \dagger$ \\
\hline Cranial embolism and/or in-farct & $8(17.4 \%)$ & $11(42.3 \%)$ & $19(26.4 \%)$ & $0.043 \dagger$ \\
\hline Lung embolism & $5(10.9 \%)$ & $7(26.9 \%)$ & $12(16.7 \%)$ & $0.104 \ddagger$ \\
\hline Surgery & $10(21.7 \%)$ & $5(19.2 \%)$ & $15(20.8 \%)$ & $>0.999 \dagger$ \\
\hline \multicolumn{5}{|l|}{ Microbiology } \\
\hline Culture negative & $15(32.6 \%)$ & $9(34.6 \%)$ & $24(33.3 \%)$ & $>0.999 \dagger$ \\
\hline Staphylococcus spp. & $13(28.3 \%)$ & $8(30.8 \%)$ & $21(29.2 \%)$ & $>0.999 \dagger$ \\
\hline Streptococcus spp. & $9(19.6 \%)$ & $3(11.5 \%)$ & $12(16.7 \%)$ & $0.517 \ddagger$ \\
\hline Enterococcus spp. & $5(10.9 \%)$ & $3(11.5 \%)$ & $8(11.1 \%)$ & $>0.999 \ddagger$ \\
\hline Other bacteria & $4(8.7 \%)$ & $3(11.5 \%)$ & $7(9.7 \%)$ & $0.698 \ddagger$ \\
\hline
\end{tabular}


Sakarya Med J 2021;11(3):561-570

KAZANCIOĞLU et al., Evaluation of Patients with Infective Endocarditis

Table 5. Predictors of mortality in patients with infective endocarditis.

\begin{tabular}{|l|c|c|c|c|c|}
\hline & Odds ratio & \multicolumn{2}{|c|}{$\% 95$ CI } & Wald & p-Value \\
\hline Invasive procedure before IE & 6.825 & 1.488 & 31.317 & 6.105 & $\mathbf{0 . 0 1 3}$ \\
\hline Lower platelet levels $\dagger$ & 1.117 & 1.039 & 1.202 & 8.866 & $\mathbf{0 . 0 0 3}$ \\
\hline Heart failure & 29.291 & 5.910 & 145.159 & 17.104 & $<\mathbf{0 . 0 0 1}$ \\
\hline$\dagger$ Effect on mortality for each decrease of $10000 / \mu \mathrm{L}$.
\end{tabular}

This study evaluated the epidemiological, clinical presentations in patients with definite IE and estimated the outcomes and changes in characteristics of the disease. Invasive procedures, heart failure, and lower platelet levels were found independent predictors for mortality.

The mean age of this cohort was ( $48.5 \pm 17.6$ years) younger than developed countries, but older than what was reported in the studies from the 1990s in Turkey and developing countries., ${ }^{9,10,12-14}$ Mean age was found closer to the mean age in a multicenter study in Turkey. ${ }^{11}$ Worldwide, a study has found an increased age among IE patients. ${ }^{4}$ Similar studies conducted in Turkey and around the world have demonstrated that males comprise the vast majority of endocarditis cases; this pattern was also observed in the present study. ${ }^{4,15,16}$ Although chronic rheumatic heart disease has been seen in decreasing rates, it is still a significant etiological manifestation in our country. ${ }^{17}$ In Turkey, HIV positivity has been increasing but there was no HIV positive patient and in our cohort. ${ }^{18}$ Some studies conducted in the United States have reported an increased IE incidence related to IVDU, but we had only two iv drug users. ${ }^{19,20}$

Blood culture positivity which one of the major criteria in the diagnosis, was low in this study similar to the studies in Turkey. ${ }^{21,22}$ BCNE (blood culture negative endocarditis) occurs more frequently in developing countries and poses a therapeutic challenge. ${ }^{7,23,24}$ Difficulties to identify the causative microorganism of IE with traditional methods are associated with high BCNE rates. Molecular and serological methods are necessary to identify microorganisms. ${ }^{25}$ There were no fastidious bacteria such as the HACEK group in this study because blood cultures and molecular methods were not processed routinely for identification of these. A review has shown that $\mathrm{BCNE}$ percentage decreased during the last decade because of improved laboratory techniques and culture methods. ${ }^{4}$ In this study, the BCNE percentage was lower in the period 2014-2017 (27.3\%), but this was not statistically significant. As $59.7 \%$ of our patients had previous use of antibiotics, we believe this was an important reason for our high number of BCNE (33.3\%). Lamas et al. reported that the BCNE rate was $40 \%$ and antibiotic use before blood culture collection was $74 \%{ }^{7}$

Staphylococcus aureus was the most frequent causative microorganism in our cohort. A systematic review showed that $\mathrm{S}$. aureus was the most common agent of IE etiology in the world, except for the Asia continent. ${ }^{6}$ A systematic review conducted by Slipczuk et al. demonstrated that staphylococcal and enterococcal IE percentages increased worldwide in the last decade. ${ }^{4}$ In this study, all enterococcal cases $(n=8)$ were seen in years between 2014-2017. Brucellosis is an endemic zoonotic disease in Turkey. Endocarditis may be a more common complication of systemic brucellosis in countries where there is a high prevalence of brucellosis and rheumatic heart disease. ${ }^{26}$ Surprisingly, in a study that evaluated complications of 700 brucellosis cases, IE was not mentioned. ${ }^{27}$ Brucella endocarditis was detected in very few patients in some studies which have a small sample size like this study in Turkey. ${ }^{22,28}$ But when the study sample size becomes larger, Brucella endocarditis cases are increased. ${ }^{17}$

Antimicrobial resistance was not a major problem in this study. Only three streptococcus isolates were resistant to penicillin. In a previous study, all streptococcus strains 
( $n=63$ ) isolated from endocarditis cases were sensitive to penicillin. ${ }^{17}$ The methicillin resistance rate among S. aureus strains $(28.6 \%)$ is similar to Turkey in general (23\%). ${ }^{29}$ We observed that $\beta$ - lactams were the most frequently used antimicrobial drugs in our study which is compatible with the resistance profile of microorganisms and current treatment guidelines. ${ }^{2}$

Surgery is crucial for optimal treatment in complicated IE. ${ }^{30}$ In this study, despite the planning of surgery in many patients, a minority of the patients were able to undergo surgery for the reason of rejection or contraindication. Surgical treatment has been reported as a protective factor for mortality in recent studies. ${ }^{16,17}$ We did not find any difference in the surgical intervention rate between the fatal and nonfatal groups. In our study, $26.4 \%$ of the patients died in hospital, whereas similar studies published in Turkey reported mortality rates of $28.6-33 \% .^{11,17,21}$ The mortality rate in our study appears to be generally high and there was no significant difference in mortality between the consecutive periods $(39.3 \%, 34.1 \%$ respectively).

In this study, older age was associated with mortality. Korem et al. found that age is the only predictor of mortality in multivariate analysis. In their study health care source of infection, CNS events, and new renal failure were associated with mortality like our study. According to our results, the presence of the comorbid condition, left-sided endocarditis, heart failure, embolic event, lower platelet level, higher urea, creatinine, and bilirubin levels were the other parameters associated with poor prognosis of IE. When looking at the laboratory findings; higher C-reactive protein (CRP), white blood cell count, creatinine, and lower albumin levels were associated with mortality in previous studies. ${ }^{13,31,32}$

Heart failure, the invasive procedure before IE, and lower platelet levels were independently associated with mortality. The largest study from Turkey has demonstrated that higher platelet and hemoglobin levels were protec- tive factors against mortality. ${ }^{17}$ Numerous studies have shown that heart failure was an independent risk factor of mortality. ${ }^{11,13,14}$ Delahaye et.al. reported that septic shock, cerebral hemorrhage, left-sided IE, lower Glasgow coma scale score, higher CRP levels, history of immunosuppression, history of heart failure, and insulin-requiring diabetes mellitus were independent predictors of mortality. ${ }^{13}$ Another study from China has shown that age $\geq 60$ years, heart failure, diabetes, and the presence of Staphylococcus aureus or gram-negative bacilli were the major risk factors related to death. ${ }^{14}$ It was reported half of the patients ( 52\%) develop heart failure in the Indian cohort. ${ }^{33}$ In this cohort, there is no relationship between causative agents and mortality. It can be explained by our small sample size and high rate of culture negativity. Siegman-Igra et al. reported that hospital-acquired and healthcare-associated IE cases had more invasive procedures (79\%) than community-acquired IE cases (69\%). ${ }^{34}$ It suggests that the importance of health-care acquisition before IE, like this study.

Because increases in the elderly population, increases in chronic illness, and increases in exposure to health care procedures; including dental procedures, intracardiac and vascular devices, hemodialysis, may increase the incidence of endocarditis and disease-related mortality. ${ }^{1,2,4}$ The two periods analysis in this study showed an increase in the invasive procedures before IE and an increasing number of enterococcal cases; on the contrary no improvement in survival. A study from Italy showed an increased healthcare exposure similar to this study. ${ }^{1}$

In conclusion, IE patients' age is becoming greater in Turkey. Culture-negative IE remains a problem in our country. Invasive procedures before IE was related to mortality. It highlights the importance of non-specific infection control measures in hospitals. The extensive use of invasive procedures can change the spectrum of microorganisms of IE etiology. Because of such changes in IE, prophylaxis, and treatment regimens should be investigated in new studies. Complications such as heart failure or CNS events 
are common and lead to higher mortality, so IE cases must be monitored closely and multidisciplinary. IE presents nonspecific symptoms and clinical findings. Because of increased health-related procedures, the diagnosis should be kept in mind in patients who have risk factors or not. Knowledge of local epidemiology and prevalence of IE is required.

\section{ACKNOWLEDGEMENTS}

This study was presented at the VII. EKMUD International Congress as an oral presentation in May 2018.

\section{Limitations of the study}

This is an observational study of a small group from one center. But our hospital is a tertiary referral center that accepts patients from many parts of Turkey. The study population was collected using ICD-10-CM codes. All patients with endocarditis may not be assessed due to diagnostic deficiencies in the hospital system resulting from user coding mistakes. Because of the retrospective design, some clinical information was limited in patients' files. Microbiological tests other than culture (Coxiella, Bartonella testing... etc.) were applied to very few patients.

\section{Authors' contributions}

SK conceived the idea of the study and coordinated the data collection. SK and EA analyzed the data and drafted the manuscript. EA and $\mathrm{HB}$ helped in drafting and revising the manuscript. $\mathrm{BO}, \mathrm{AB}, \mathrm{AA}$ participated in data collection and analysis. All authors have read and approved the final manuscript.

The authors declare no conflicts of interest.

This research did not receive any specific grant from funding agencies in the public, commercial, or not-for-profit sectors.

The data that support the findings of this study are available from the corresponding author, $[\mathrm{SK}]$, upon request.

\section{Ethical Approval}

Ethics committee approval was obtained for this study from Ankara Numune Training and Research Hospital (confirmation date and number: 29.03.2017, $1320 / 2017)$. This study was conducted by the principles of the Declaration of Helsinki. 
Sakarya Med J 2021;11(3):561-570

KAZANCIOĞLU et al., Evaluation of Patients with Infective Endocarditis

\section{References}

1. Cresti A, Chiavarelli $M$, Scalese M, Nencioni C, Valentini S, Guerrini F, et al. Epidemiological and mortality trends in infective endocarditis, a 17-year population-based prospective study. Cardiovascular diagnosis and therapy. 2017;7(1):27.

2. Habib G, Lancellotti P, Antunes MJ, Bongiorni MG, Casalta J-P, Del Zotti F, et al. 2015 ESC guidelines for the management of infective endocarditis: the task force for the management of infective endocarditis of the European Society of Cardiology (ESC) endorsed by: European Association for Cardio-Thoracic Surgery (EACTS), the European Association of Nuclear Medicine (EANM). European heart journal. 2015;36(44):3075-128.

3. Bentata Y. Physiopathological approach to infective endocarditis in chronic hemodialysis patients: left heart versus right heart involvement. Renal failure. 2017;39(1):432-9.

4. Slipczuk L, Codolosa JN, Davila CD, Romero-Corral A, Yun J, Pressman GS, et al. Infective endocarditis epidemiology over five decades: a systematic review. PloS one. 2013;8(12):e82665.

5. Cabell CH, Heidenreich PA, Chu VH, Moore CM, Stryjewski ME, Corey GR, et al. Increasing rates of cardiac device infections among Medicare beneficiaries: 1990-1999. American heart journal. 2004;147(4):582-6.

6. Vogkou CT, Vlachogiannis NI, Palaiodimos L, Kousoulis AA. The causative agents in infective endocarditis: a systematic review comprising 33,214 cases. European journal of clinical microbiology \& infectious diseases. 2016;35(8):1227-45.

7. Lamas CC, Fournier P-E, Zappa M, Brandão TJ, Januário-da-Silva CA, Correia MG, et al. Diagnosis of blood culture-negative endocarditis and clinical comparison between blood culture-negative and blood culture-positive cases. Infection. 2016;44(4):459-66.

8. Chu VH, Cabell CH, Benjamin Jr DK, Kuniholm EF, Fowler Jr VG, Engemann J, et al. Early predictors of in-hospital death in infective endocarditis. Circulation. 2004;109(14):1745-9.

9. Letaief A, Boughzala E, Kaabia N, Ernez S, Abid F, Chaabane TB, et al. Epidemiology of infective endocarditis in Tunisia: a 10-year multicenter retrospective study. International Journal of Infectious Diseases. 2007;11(5):430-3.

10. Rasmussen RV, Snygg-Martin U, Olaison L, Andersson R, Buchholtz K, Larsen CT, et al. One-year mortality in coagulase-negative Staphylococcus and Staphylococcus aureus infective endocarditis. Scandinavian journal of infectious diseases. 2009;41(6-7):456-61.

11. Leblebicioglu H, Yilmaz H, Tasova Y, Alp E, Saba R, Caylan R, et al. Characteristics and analysis of risk factors for mortality in infective endocarditis. European journal of epidemiology. 2006;21(1):25-31.

12. Toyoda N, Chikwe J, Itagaki S, Gelijns AC, Adams DH, Egorova NN. Trends in infective endocarditis in California and New York State, 1998-2013. Jama. 2017;317(16):1652-60.

13. Delahaye F, Alla F, Béguinot I, Bruneval P, Doco-Lecompte T, Lacassin F, et al. In-hospital mortality of infective endocarditis: prognostic factors and evolution over an 8-year period. Scandinavian journal of infectious diseases. 2007;39(10):849-57.

14. Zhu W, Zhang $Q$, Zhang J. The changing epidemiology and clinical features of infective endocarditis: a retrospective study of 196 episodes in a teaching hospital in China. BMC cardiovascular disorders. 2017;17(1):113.

15. Tuğcu A, Yildirimtürk O, Baytaroğlu C, Kurtoğlu H, Köse O, Sener M, et al. Clinical spectrum, presentation, and risk factors for mortality in infective endocarditis: a review of 68 cases at a tertiary care center in Turkey. Turk Kardiyol Dern Ars. 2009;37(1):9-18.

16. Murdoch DR, Corey GR, Hoen B, Miró JM, Fowler VG, Bayer AS, et al. Clinical presentation, etiology, and outcome of infective endocarditis in the 21st century: the International Collaboration on Endocarditis-Prospective Cohort Study. Archives of internal medicine. 2009;169(5):463-73.

17. Şimşek-Yavuz S, Şensoy A, Kaşıkçıoğlu H, Çeken S, Deniz D, Yavuz A, et al. Infective endocarditis in Turkey: aetiology, clinical features, and analysis of risk factors for mortality in 325 cases. International Journal of Infectious Diseases. 2015;30:106-14.
18. Hiv/aids nedir? Available at: http://www.hatam.hacettepe.edu.tr/AIDS_web-2017.pdf [Last accessed February,2020]

19. Wurcel AG, Anderson JE, Chui KK, Skinner S, Knox TA, Snydman DR, et al., editors. Increasing infectious endocarditis admissions among young people who inject drugs. Open forum infectious diseases. 2016; Vol. 3. No. 3. Oxford University Press.

20. Cooper HL, Brady JE, Ciccarone D, Tempalski B, Gostnell K, Friedman SR. Nationwide increase in the number of hospitalizations for illicit injection drug use-related infective endocarditis. Clinical Infectious Diseases. 2007;45(9):1200-3.

21. Elbey MA, Akdağ S, Kalkan ME, Kaya MG, Sayın MR, Karapinar H, et al. A multicenter study on experience of 13 tertiary hospitals in Turkey in patients with infective endocarditis. Anadolu Kardiyol Derg. 2013;13(6):523-7.

22. Sucu M, Davutoğlu V, Özer O, Aksoy M. Epidemiological, clinical and microbiological profile of infective endocarditis in a tertiary hospital in the South-East Anatolia Region. Congestive heart failure. 2010;23:31.9.

23. Garg N, Kandpal B, Garg N, Tewari S, Kapoor A, Goel P, et al. Characteristics of infective endocarditis in a developing country-clinical profile and outcome in 192 Indian patients, 1992-2001. International journal of cardiology. 2005;98(2):253-60.

24. Xu H, Cai S, Dai H. Characteristics of infective endocarditis in a tertiary hospital in East China. PloS one. 2016;11(11):e0166764.

25. Barrau K, Boulamery A, Imbert G, Casalta J-P, Habib G, Messana T, et al. Causative organisms of infective endocarditis according to host status. Clinical microbiology and infection. 2004;10(4):302-8.

26. Cetinkaya Y, Akova M, Akalın H, Aş̧ı̆ğlu S, Hayran M, Uzuns Ö, et al. A retrospective review of 228 episodes of infective endocarditis where rheumatic valvular disease is still common. International journal of antimicrobial agents. 2001;18(1):1-7.

27. Kayaaslan B, Bastug A, Aydin E, Akinci E, But A, Aslaner H, et al. A long-term survey of brucellosis: Is there any marker to predict the complicated cases? Infectious Diseases. 2016;48(3):215-21.

28. Gursul NC, Vardar I, Demirdal T, Gursul E, Ural S, Yesil M. Clinical and microbiological findings of infective endocarditis. The Journal of Infection in Developing Countries. 2016;10(05):478-87.

29. Central Asian and European Surveillance of Antimicrobial Resistance. Annual report 2019. https://www.euro.who.int/en/health-topics/disease-prevention/antimicrobial-resistance/ publications/2019/central-asian-and-european-surveillance-of-antimicrobial-resistance.-annual-report-2019. [Last accessed February 2020]

30. Baddour LM, Wilson WR, Bayer AS, Fowler VG, Tleyjeh IM, Rybak MJ, et al. Infective endocarditis in adults: diagnosis, antimicrobial therapy, and management of complications: a scientific statement for healthcare professionals from the American Heart Association. Circulation. 2015: CIR. 0000000000000296.

31. Roca B, Marco JM. Presentation and outcome of infective endocarditis in Spain: a retrospective study. International Journal of infectious diseases. 2007;11(3):198-203.

32. Wallace S, Walton B, Kharbanda R, Hardy R, Wilson A, Swanton R. Mortality from infective endocarditis: clinical predictors of outcome. Heart. 2002;88(1):53-60.

33. Khanal B, Harish BN, Sethuram KR, Srinivasan S. Infective endocarditis: report of a prospective study in an Indian hospital. Trop. Doct. 2002;32(2):83-5.

34. Siegman-Igra Y, Koifman B, Porat R, Porat D, Giladi M. Healthcare associated infective endocarditis: a distinct entity. Scandinavian journal of infectious diseases. 2008;40(67):474-80. 